\title{
Hemochromatosis as a cause of central primary Amenorrhea: A literature review and case report
}

\author{
Gustavo dos Santos Raupp ', Vitória Lucietto Piccinini', Marta Ribeiro Hentschke', Mona Lúcia Dall'Agno1, \\ Ariane Tieko Frare Kira', Fernanda Braga Seganfredo', Nathalia da Cunha Rossato', Alvaro Petracco ${ }^{1,2}$, \\ Mariangela Badalotti 1,2
}

'Pontificia Universidade Católica do Rio Grande do Sul, Escola de Medicina, Porto Alegre, RS, Brasil ${ }^{2}$ Fertilitat - Centro de Medicina Reprodutiva, Porto Alegre, RS, Brasil

The study was carried out at Hospital São Lucas, Pontifícia Universidade Católica do Rio Grande do Sul, Porto Alegre, RS, Brasil.

\begin{abstract}
Introduction: Hereditary hemochromatosis $(\mathrm{HH})$ is a genetic disease that causes systemic iron overload. The excess of iron accumulates in several organs, leading to organ dysfunction. Therefore, the excess of iron deposition might create an endocrine impairment, and can further lead to hypogonadism and, rarely, to amenorrhea. In this study, we aim to report a rare cause of HH and primary amenorrhea, with the help of clinical investigations. Case Description: This study is based on a single patient who was diagnosed with amenorrhea. The patient had a previous history of $\mathrm{HH}$, type I diabetes mellitus, and chronic liver disease. The physical and hormonal investigations were normal, and her karyotype was 46 XX. A magnetic resonance imaging (MRI) demonstrated a diffuse reduction of the pituitary tissue signal, which might resemble HH. Discussion: The diagnosis of $\mathrm{HH}$ is based on a biochemical and genetic evaluation. The treatment includes regular phlebotomies and the control of comorbidities. In most of the cases, the hypogonadotropic hypogonadism leads to amenorrhea due to a pituitary impairment. However, a rare appearance of amenorrhea without hypogonadism may also be possible. Hence, the investigation of $\mathrm{HH}$ should be suggested incases of primary amenorrhea. The early diagnosis of $\mathrm{HH}$ is crucial to prevent the morbidity and mortality in patients with these clinical features.
\end{abstract}

Keywords: amenorrhea; diabetes mellitus; hemochromatosis; menstruation disturbances, and pituitary gland.

\section{Introduction}

Primary amenorrhea is defined as the absence of menarche by the age of 13 years, five years after thelarche, or without secondary sexual characteristics by the age of 15 years'. Primary amenorrhea is multifactorial. Can be caused by an anatomical defect in the lower genital tract, primary hypogonadism, impairment in the hypothalamic-pituitary axis, and by an endocrine impairment ${ }^{2}$. The prevalence of the ovarian disorder is mostly predominant $(48.5 \%)$, followed by congenital abnormalities (16.2\%), gonadotropin-releasing hormone (GnRH) deficiency (8.3\%), and a constitutional delay of puberty $(6 \%)^{3}$. Hereditary hemochromatosis $(\mathrm{HH})$ is a genetic disorder that causes iron overload in the bloodstream, leading to systemic organ damage. The clinical manifestations range from asymptomatic, or nonspecific systemic symptoms, such as weakness, lethargy, and weight loss to specific organ-related symptoms including cirrhosis, hepatomegaly, arthritis, diabetes mellitus, cardiomyopathy, congestive heart failure, arrhythmias, hypogonadism, and skin pigmentation. ${ }^{4,5}$ Patients with hemochromatosis can develop amenorrhea due to hypogonadism. The high iron serum level may result in parenchymal iron overload and subsequent tissue damage. Also, the iron deposition at pituitary gland induces pituitary-gonadal dysfunction leading to the gonadal failure, which further causes amenorrhea. ${ }^{6,7}$

The physiopathology of $\mathrm{HH}$ is related to hepcidin, which is a peptide produced by the hepatocytes responsible for iron homeostasis. Hepcidin normally binds to ferroportin to export intracellular iron from spleen to plasma. Decreased hepcidin levels or resistance behavior of hepcidin causes $\mathrm{HH}$. The abnormal interaction between hepcidin and ferroportin

Financial support: None.

Conflicts of interest: The authors declare no conflicts of interest.

Received: 03.09.2019

Accepted: 01.06.2020

Copyright Raupp et al. This is an Open Access article distributed under the terms of the Creative Commons Attribution License, which permits unrestricted use, distribution, and reproduction in any medium, provided the original work is properly cited. 
causes an increased iron efflux from hepatocytes, further leading to an excess iron concentration in the bloodstream. When iron is in excess, it does not bind to transferrin anymore, and hence it is named as non-transferrin bound iron (NTBI). The NTBI is rapidly taken up by hepatocytes, cardiomyocytes, pancreatic, and pituitary cells. The deposition of NTBI on these sites generate reactive oxygen species (ROS), which further leads to organ damage. The other possible mechanism for physiopathology is the impairment of ferroportin, which affects the cellular iron export function. ${ }^{8,9}$

The $\mathrm{HH}$ is classified in different types based on genetic mutations. Type $1 \mathrm{HH}$, or classical form, is primarily related to an HFE mutation. It occurs due to an alteration in hepcidin metabolism, which consists of the replacement of tyrosine with cysteine at the site of 282 (C282Y) or aspartate with histidine at amino acid 63 (H63D). It can appear as homozygosity (C282Y/C282Y) or as heterozygosity (C282Y/H63D). Type 2A, 2B, 3, and 4B are related to HJV, HAMP, TFR2, and SLC40A1 mutations, respectively. The non-HFE mutations are related to ferroportin metabolism due to SLC40A1 mutation..$^{8-10}$ The diagnosis of $\mathrm{HH}$ can be possible based on increased iron deposition regardless of symptoms. The essential examination includes serum ferritin levels and transferrin saturation, besides HFE mutation analysis and liver biopsy. ${ }^{11}$

\section{Case description}

This research is based on a 17-years-old female patient, who was referred to São Lucas Hospital, outpatient clinic, due to primary amenorrhea. The patient had a medical history of $\mathrm{HH}$ with an $\mathrm{H} 63 \mathrm{D}$ mutation and was recently diagnosed with type I diabetes mellitus. The physical examination revealed normal weight and height (53,8kg and 1,60m), adequate Tanner Scale (M3P4), and normal external genitalia. There was no sign of hyperandrogenism (hirsutism or acne) or palpable inguinal masses. The speculum was not used during the examination because the patient had not started the sexual life untill then. The pelvic ultrasound identified normal uterus and ovaries. The abdominal ultrasound reports signs of chronic liver disease. The laboratory investigations revealed the thyroid-stimulating hormone $(\mathrm{TSH})$ as $1,68 \mathrm{IU} / \mathrm{mL}$, prolactin as $9,8 \mathrm{ng} / \mathrm{mL}$, follicle-stimulating hormone $(\mathrm{FSH})$ as $4,2 \mathrm{mlU} / \mathrm{mL}$, luteinizing hormone $(\mathrm{LH})$ as $2,9 \mathrm{mlU} / \mathrm{mL}$, and estradiol as $41,7 \mathrm{pg} / \mathrm{mL}$. The karyotype of the patient was 46XX.The radiography of the left hand and wrist indicated a bone age compatible with chronological age. However, the bone mineral density (BMD) indicates a reduction in bone mass for age, according to the International Society for Clinical Densitometry, (Z-score): right femur neck (-3.4), total femur (-3.7) and lumbar spine, L1-L4 (-4.4).

We further perform the Estrogen-Progesterone Challenge Test by considering the normal reports of all the laboratory tests and pelvic ultrasound. The Estrogen-Progesterone Challenge Test was positive. During the investigation, the MRI was requested. The investigation revealed a diffuse reduction of the pituitary tissue signal, which was compatible with $\mathrm{HH}$, further confirming the diagnosis of the central amenorrhea. The gynecology team opted to start a hormone replacement therapy regimen with $1 \mathrm{mg}$ of estradiol during the $1^{\text {st }}$ to $14^{\text {th }}$ day of the cycle, and $1 \mathrm{mg}$ of estradiol associated with $0.5 \mathrm{mg}$ of norethisterone acetate during $15^{\text {th }}$ to $28^{\text {th }}$ day of the cycle. The hormonal therapy was associated with calcium carbonate (500mg) taken as one tablet every 12 hours, vitamin D (200IU) taken as 15 drops per day, and sodium ibandronate (150mg) taken as one tablet per week, respectively. The patient was further assessed by a hematologist, who indicated regular phlebotomies, and by a gastroenterologist, who assisted the monitoring of liver function. However, the patient evolved with significant worsening of the hepatic function with cirrhosis as a consequence of the $\mathrm{HH}$, required and perfomed a liver transplant. At this moment, the patient is stills in follow-up routine at the gynecology and gastroenterologist outpatient clinic, receiving an appropriate insulin regimen for diabetes, and immunomodulators due to transplantation, as per the medical prescription.

\section{Discussion}

This study reports a case of primary amenorrhea due to $\mathrm{HH}$. Amenorrhea in patients with $\mathrm{HH}$ must be considered for the investigation. It is well known that $\mathrm{HH}$ causes infertility in women due to the high deposition of iron in the pituitary gland and gonads, leading to an alteration in their functions. The early diagnosis of $\mathrm{HH}$ is essential because the correct therapy with phlebotomies, hormones, and gonadotropins might restore the hypothalamic-pituitary-gonadal axis and the reproductive function. However, the reproductive system may not recover when the disease is recognized after tissue damage. ${ }^{12}$

The investigation of amenorrhea requires an anamnesis with particular attention to the duration of amenorrhea, family history of delayed puberty, contraceptive history, the practice of intense physical exercises, massive weight loss or weight gain, the presence of stressful events, drug abuse, presence of cyclic pelvic pain, and symptoms of virilization or galactorrhea. During the physical examination, it is important to observe the sign of hyperandrogenism (acne, hirsutism), features of Turner syndrome, the presence of pelvic masses, genital malformations, and stage on the Tanner Scale. The complementary exams include the determination of bone age by radiography of left hand and wrist to exclude constitutional delay, hormonal dosage (TSH, prolactin, $\mathrm{FSH})$, and pelvic ultrasound to determine the presence or absence of the uterus. In case the patient does not have a uterus, the karyotype is required, such as testosterone level. If the uterus is present and the uterovaginal causes are excluded, then the investigation should proceed in a similar way as it is in the cases of secondary amenorrhea. In the case of high FSH levels, which indicates an early follicular insufficiency, 
the karyotype should be requested to rule out Turner syndrome or genetic mosaicism. If the level of FSH is normal or decreased, and TSH and prolactin are normal, then the investigation for hypogonadotropic hypogonadism must be considered. Henceforth, in this investigation, an evaluation of the hypothalamic-pituitary axis is required. ${ }^{13}$

The initial approach to the diagnosis of $\mathrm{HH}$ in symptomatic, first-degree relative, and asymptomatic patients starts with the analyze serum transferrin saturation (TS), and ferritin. If TS is greater than or equal to $45 \%$ and/or ferritin level is elevated (over $200 \mathrm{ng} / \mathrm{mL}$ in men and over $150 \mathrm{ng} / \mathrm{mL}$ in women), then HFE genotype is required. No further investigation is required if TS is lower than $45 \%$. If the genetic test identifies C282Y mutation, then it is a must to investigate the ferritin level and the liver enzymes. If the ferritin level is lower than $1000 \mathrm{ng} / \mathrm{mL}$ and liver enzymes are normal, then the patient undergoes phlebotomy without a liver biopsy. On the other hand, if C282Y mutation is identified, but ferritin level is greater than $1000 \mathrm{ng} / \mathrm{mL}$ and/or liver enzymes are abnormal, then liver a biopsy is mandatory to exclude hepatocellular carcinoma. If the genotype identifies heterozygote compound, C282Y-H63-D or non C282Y, then the patient may need a biopsy, and hematologic diseases must be ruled out.9,14,15

The liver biopsy has been replaced with genetic testing or MRI, and it is no longer necessary for diagnosis. It is only mandatory in a patient with high-risk, such as advanced liver disease or hepatocellular carcinoma. ${ }^{9,16}$

The therapeutic strategy should proceed toward the reduction of iron overload to reduce the possibility of $\mathrm{HH}$. It consists of regular phlebotomies in both symptomatic and asymptomatic patients. Some clinical features might improve with the treatment, such as malaise, fatigue, skin pigmentation, insulin requirements, and abdominal pain. However, destructive arthritis, insulin-dependent diabetes, hypogonadism, and advanced cirrhosis may be irreversible. ${ }^{17,18}$ The phlebotomy should be recognizedand may tolerate weekly regimen, and target levels of ferritin level should be 50-100ng/ $\mathrm{mL}$. In case of intolerance or contraindication to phlebotomies, an iron chelator is an option. 8,9,16

The $\mathrm{HH}$ usually leads to endocrine dysfunction, ultimately accelerated diabetes, hypothyroidism, and hypogonadism. The iron frequently deposits in anterior pituitary cells and in posterior pituitary cells very rarely. ${ }^{19,20} \mathrm{As}$ a result, the excess deposition of iron decreases several hormones and leads to both primary and secondary hypogonadism. Though the secondary hypogonadism is more common, which leads the impairment in the production and release of gonadotropins in the pituitary, and GnRH in the hypothalamus. ${ }^{12,20,21}$ The hypogonadism is more common in men than in women. It has been previously established that there was no sign of hypogonadism has been found in women with $\mathrm{HH}$,such as loss of libido or early menopause.22Another study demonstrated that the 36 cases among the 68 symptomatic patients, were shown the sign of hypogonadism, and the

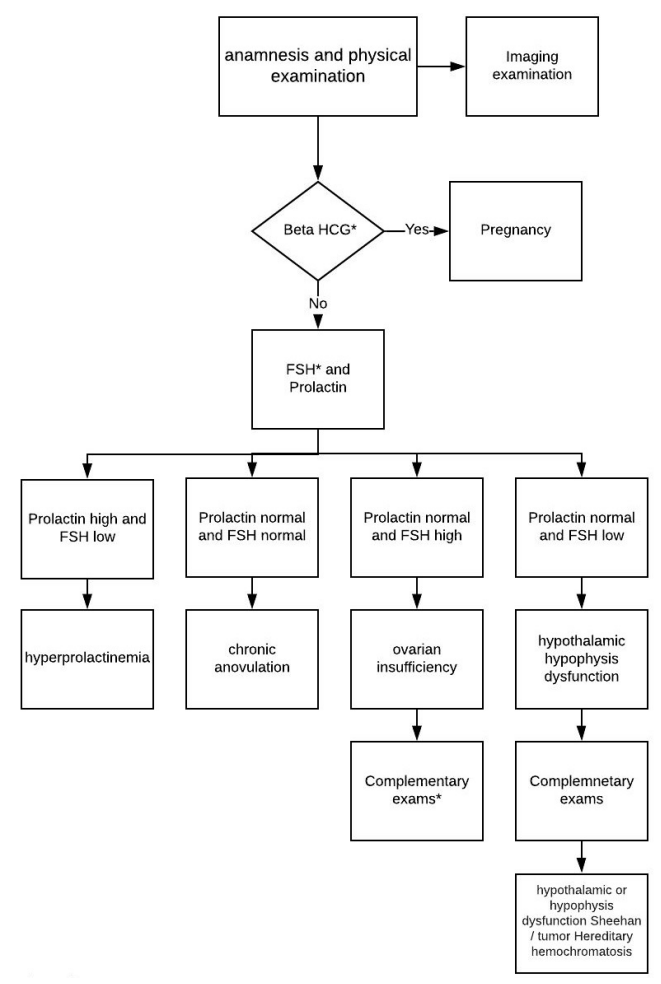

Figure 1.

*Legend: FSH. Follicle Stimulating Hormone Beta HCG. Human Chorionic Gonadotropin (hCG), $\beta$-Subunit

*follow-up according to premature ovarian insufficiency protocol

Adapted from Tratado de Ginecologia da Febrasgo - Fernandes, $1^{\circ}$ edição, 2018, Elsevier. 
remaining 15 cases were shown the sign of amenorrhea. The following study was carried out on 109 cases; among 41 cases were asymptomatic and 68 cases had symptoms ${ }^{22,23}$ The main tests for the differential diagnosis of amenorrhea include serum FSH, prolactin, estradiol E2, TSH, Free thyroxine (free T4), and human chorionic gonadotropin (beta-HCG). Moreover, the pelvic ultrasound and hysteroscopy were applied for the investigation of anatomical causes (Figure 1).

Furthermore, the studies suggested that the pituitary gland and hypothalamus are sensitive sites for iron toxicity. Also, the excess of iron causes oxidative stress by an increase in the generation of ROS. It further causes an impairment of the microenvironment, and the enzymatic antioxidant defense mechanism ultimately leads to the reduction of the reproductive potential in women. ${ }^{24}$ Several data published in the literature suggest that $\mathrm{HH}$ can be a cause of hypogonadotropic hypogonadism due to an irreversible pituitary injury. The gonadal function can be stimulated by gonadotropinsand might maintain or restore the reproductive capacity of thepatients.

Therefore, we conclude that the diagnosis and investigation of amenorrhea is a complex process. The investigation of $\mathrm{HH}$ must be considered if a case is recognized with the presence of hypogonadotropic hypogonadism. The prompt treatment is recommended, as it can change both the progression and the prognosis of the disease. ${ }^{24,25}$

\section{Acknowledgements}

We thank all the doctors and students that were clinically involved in this case.

\section{References}

1. Klein DA, Poth MA. Amenorrhea: an approach to diagnosis and management. Am Fam Physician. 2013;87(11):781-8. PMid:23939500.

2. Deligeoroglou E, Athanasopoulos N, Tsimaris P, Dimopoulos KD, Vrachnis N, Creatsas G. Evaluation and management of adolescent amenorrhea. Ann N Y Acad Sci. 2010;1205(1):23-32. http://dx.doi.org/10.1111/j.1749-6632.2010.05669.x. PMid:20840249.

3. Timmreck LS, Reindollar RH. Contemporary issues in primary amenorrhea. Obstet Gynecol Clin North Am. 2003;30(2):287-302. http://dx.doi.org/10.1016/S0889-8545(03)00027-5. PMid:12836721.

4. Pelusi C, Gasparini DI, Bianchi N, Pasquali R. Endocrine dysfunction in hereditary hemochromatosis. J Endocrinol Invest. 2016;39(8):83747. http://dx.doi.org/10.1007/s40618-016-0451-7. PMid:26951056.

5. Porto G, Brissot P, Swinkels D, Zoller H, Kamarainen O, Patton S, et al. EMQN best practice guidelines for the molecular genetic diagnosis of hereditary hemochromatosis (HH). Eur J Hum Genet. 2016;24(4):479-95. http://dx.doi.org/10.1038/ejhg.2015.128. PMid:26153218.

6. Goldschmidt H, Spiera H, Schumacher H Jr, Zaroulis CG. Idiopathic hemochromatosis presenting as amenorrhea and arthritis. Am J Med. 1987;82(5):1057-9.

7. McDermott JH, Walsh CH. Hypogonadism in hereditary hemochromatosis. J ClinEndocrinol Metab. 2005;90(4):2451-5.

8. Brissot P, Cavey T, Ropert M, Guggenbuhl P, Loréal O. Genetic hemochromatosis: Pathophysiology, diagnostic and therapeutic management. Presse Med. 2017;46(12):e288-95. http://dx.doi.org/10.1016/j.Ipm.2017.05.037. PMid:29158016.

9. Bacon BR, Adams P, Kowdley K, Powell L, Tavill A, American Association for the Study of Liver Diseases. Diagnosis and management of hemochromatosis: 2011 Practice Guideline by the American Association for the Study of Liver Diseases. Hepatology. 2011;54(1):32843. http://dx.doi.org/10.1002/hep.24330. PMid:21452290.

10. Pietrangelo A, Caleffi A, Henrion J, Ferrara F, Corradini E, Kulaksiz H, et al. Juvenile hemochromatosis associated with pathogenic mutations of adult hemochromatosis genes. Gastroenterology. 2005;128(2):470-9. http://dx.doi.org/10.1053/j.gastro.2004.11.057. PMid:15685557.

11. Crownover BK, Covey CJ. Hereditary hemochromatosis. Am Fam Physician. 2013;87(3):183-90.

12. Tweed MJ, Roland JM. Haemochromatosis as an endocrine cause of subfertility. BMJ. 1998;316(7135):915-6. http://dx.doi. org/10.1136/bmj.316.7135.915. PMid:9552844.

13. Dickerson EH, Raghunath AS, Atkin SL. Initial investigation of amenorrhoea. BMJ. 2009;339:455-7.

14. Schmitt B, Golub RM, Green R. Screening primary care patients for hereditary hemochromatosis with transferrin saturation and serum ferritin level: systematic review for the American College of Physicians. Ann Intern Med. 2005;143(7):522-36. http:// dx.doi.org/10.7326/0003-4819-143-7-200510040-00011. PMid:16204165.

15. Qaseem A, Aronson M, Fitterman N, Snow V, Weiss KB, Owens DK, Clinical Efficacy Assessment Subcommittee of the American College of Physicians. Screening for hereditary hemochromatosis: a clinical practice guideline from the American College of Physicians. Ann Intern Med. 2005;143(7):517-21. http://dx.doi.org/10.7326/0003-4819-143-7-200510040-00010. PMid:16204164.

16. European Association for the Study of the Liver. EASL Clinical Practice Guidelines for HFE Hemochromatosis. J Hepatol. 2010;53(1):322. http://dx.doi.org/10.1016/j.jhep.2010.03.001.

17. Powell LW, George D, McDonnell SM, Kowdley KV. Diagnosis of hemochromatosis. Ann Intern Med. 1998. 129(11):925-31.

18. Pietrangelo A. Hereditary Hemochromatosis: pathogenesis, diagnosis, and treatment. Gastroenterology. 2010;139(2):393-408. e2. http://dx.doi.org/10.1053/j.gastro.2010.06.013. PMid:20542038. 
19. Fujisawa I, Morikawa M, Nakano Y, Konishi J. Hemochromatosis of the pituitary gland: MR imaging. Radiology. 1988;168(1):213-4. http://dx.doi.org/10.1148/radiology.168.1.3380960. PMid:3380960.

20. Sondag MJ, Wattamwar AS, Aleppo G, Nemeth AJ. Case 179: Hereditary hemochromatosis. Radiology. 2012;262(3):1037-41. http:// dx.doi.org/10.1148/radiol.11102324. PMid:22357904.

21. Naredi N, Seth A, Sharma A. Iron Overload: A cause of primary Amenorrhea. Med J Armed Forces India. 2011;67(1):86-7. http:// dx.doi.org/10.1016/S0377-1237(11)80029-8. PMid:27365772.

22. Kelly T, Edwards CQ, Meikle AW, Kushner JP. Hypogonadism in Hemochromatosis: Reversal with Iron Depletion. Ann Intern Med. 1984;101(5):629-32. http://dx.doi.org/10.7326/0003-4819-101-5-629. PMid:6435491.

23. Singer ST, Sweeters N, Vega O, Higa A, Vichinsky E, Cedars M. Fertility potential in thalassemia major women: current findings and future diagnostic tools. Ann N Y Acad Sci. 2010;1202(1):226-30. http://dx.doi.org/10.1111/j.1749-6632.2010.05583.x. PMid:20712797.

24. Adams P, Speechley M, Kertesz A. Long-term survival analysis in hereditary hemochromatosis. Gastroenterology. 1991;101(2):36872. http://dx.doi.org/10.1016/0016-5085(91)90013-B. PMid:2065912.

25. Farina G, Pedrotti C, Cerani P, Rovati A, Strada E, Bergamaschi G, et al. Successful pregnancy following gonadotropin therapy in a young female with juvenile idiopathic hemochromatosis and secondary hypogonadotropic hypogonadism. Haematologica. 1955;80(4):335-7. PMid:7590503.

\section{Correspondence}

Marta Ribeiro Hentschke

Hospital São Lucas, Pontificia Universidade Católica do Rio Grande do Sul

Av. Ipiranga, 6690, $2^{\circ}$ Andar, Laboratório 19

CEP: 90610-000, Porto Alegre, RS, Brasil

E-mail: martarh@yahoo.com.br; martahentschke@gmail.com

\section{Author information}

Marta Ribeiro Hentschke is gynecologist and obstetrician, with PhD in medicine and Post-doctoral degree in Reproductive Medicine at Pontifical Catholic University of Rio Grande do Sul (PUCRS) and Fertilitat - Reproductive Medicine Center. She is also a professor at the School of Medicine/ PUCRS, Porto Alegre, Brazil. Gustavo dos Santos Raupp and Vitoria Lucietto Piccinini are medical residents of Gynecology and Obstetrics at the São Lucas Hospital/PUCRS (HSL/PUCRS), Porto Alegre, Brazil. Nathalia da Cunha Rossato is gynecologist and obstetrician, with specialization in Mastology at HSL/PUCRS. She is also a Master student at PUCRS. Ariane Tieko Frare Kira is gynecologist and obstetrician, with specialization in Human Reproduction at HSL/PUCRS and Fertilitat - Reproductive Medicine Center; she took part in a Fellowship in in vitro fertilization at the Valencian Institute of Infertility. She is also Director of Afetiv - Gynecology and Human Reproduction and Physician Assistant at Fertilitat Reproductive Medicine Center. Mona Lúcia Dall'Agno is gynecologist and obstetrician, with specialization in Human Reproduction and Gynecological Endocrinology, with Master degree in Gynecology and Obstetrics at Federal University of Rio Grande do Sul (UFRGS). She is also Professor at the the School of Medicine/University of Caxias do Sul (UCS) and preceptor of the Medical Residency Program - Gynecology and Obstetrics/General Hospital of Caxias do Sul (HGCS). Fernanda Braga Seganfredo is a clinical physician; with PhD in Medicine and Health Science (PUCRS). Alvaro Petracco is gynecologist and obstetrician; with PhD in Health Sciences at Faculty of Medicine of São José do Rio Preto (FAMERP). He is also Director of Fertilitat-Reproductive Medicine Center, Porto Alegre, Brazil. Mariangela Badalotti is gynecologist and obstetrician, with PhD in Pathology at Federal University of Health Sciences of Porto Alegre (UFCSPA); Professor at the School of Medicine/PUCRS. She is also Director of Fertilitat Reproductive Medicine Center, Porto Alegre, Brazil.

\section{Authors contribution}

GSR - Substantial contributions to conception and design. MRH - Critical review of the intellectual content; final approval of the version to be published. VLP - Substantial contributions to conception and design. MLDA - Critical review of the intellectual content. ATFK - Critical review of the intellectual content. FBS - Critical review of the intellectual content. NCR - Critical review of the intellectual content. AP - Critical review of the intellectual content; final approval of the version to be published. MB - Critical review of the intellectual content; final approval of the version to be published. 